\title{
Desenvolvimento rural e economia local: evolução e diferenciação dos sistemas agrários e o surgimento e a consolidação da rizicultura no município de Itaqui
}

\author{
Juliana Vargas Ceretta ${ }^{1}$ \\ Marlise Amália Reinehr Dal Forno ${ }^{2}$ \\ Márcia dos Santos Ramos Berreta ${ }^{3}$ \\ Daniela Garcez Wives ${ }^{4}$ \\ Luciano Silva Figueiredo ${ }^{5}$
}

\section{Resumo}

Esta pesquisa historiográfica do Município de Itaqui analisou como as evoluções dos diferentes sistemas agrários influenciaram no surgimento e na consolidação da rizicultura na economia local. Para isso, reconstituiu-se a evolução dos sistemas agrários do município de Itaqui, diferenciando-os, conforme o período histórico, e apontando os fatores sociais, econômicos, políticos e ambientais que condicionaram o surgimento e a consolidação da rizicultura no Município. Na metodologia, apresenta-se num estudo qualitativo e historiográfico, alicerçado na abordagem dos sistemas agrários. A pesquisa apontou que o sistema agrário de Itaqui está estruturado em duas fases: a pré-capitalista e capitalista monopolista financeira. A partir disso, pode-se concluir que a base econômica municipal está diretamente relacionada com o tipo de sistema agrário implantado nesse Município, o que reflete na primeira colocação do ranking nacional na produção de arroz na safra de 2012/2013. Além dessa produção, Itaqui possui uma importante estrutura industrial para o armazenamento e beneficiamento do grão, consolidando a prática desse monocultivo na região Fronteira Oeste.

Palavras-chave: Itaqui. Rizicultura. Sistemas Agrários.

\section{Abstract}

This historical research was performed in the city of Itaquiand analyzed how the evolution of different agrarian systems influenced the dawn and the consolidation of riceculture in the local economy. To this end, we reconstructed the evolution of the agrarian systems of the city, differentiating them according to their historical period,

\footnotetext{
${ }^{1}$ Tecnóloga em Desenvolvimento Rural pela Universidade Federal do Rio Grande do Sul/UFRGS. julianaceretta@bol.com.br

2 Doutora em Geografia pela Universidade Federal do Rio Grande do Sul/UFRGS e Professora no Programa de Pós-Graduação em Desenvolvimento Rural - PGDR/UFRGS. marlise.forno@ufrgs.br

${ }^{3}$ Doutora em Geografia pela Universidade Federal do Rio Grande do Sul/UFRGS. marcia.berreta@ufrgs.br

${ }^{4}$ Doutora em Desenvolvimento Rural pela Universidade Federal do Rio Grande do Sul/UFRGS. garcezd@gmail.com

${ }^{5}$ Doutor em Biologia pela Universidade Federal do Rio Grande do Sul/UFRGS e Professor no Programa de Pós-Graduação em Desenvolvimento Rural/UFRGS. lucfigueireddo@uol.com.br
} 
and we pointed out the social, economic, political and environmental factors that directed the emergence and the consolidation of the riceculture in that city. The methodology consists in a qualitative and historiographical study based in the agrarian systems approach. The research pointed out that Itaqui's agrarian system may be structured into two phases, i.e., pre-capitalist and financial monopolist capitalist. Thereafter, we can conclude that the economic base of this city is directly related to the type of farming system there implanted which in turns reflects in Itaquibeing in the first position of the national rice production ranking of 2012/13. Beyond production, the city constituted an imposing industrial structure for the storage and processing of grain, consolidating the practice of this monoculture in the Border West region of the state of Rio Grande do Sul, Brazil.

Keywords: Agrarian systems. Itaqui. Riceculture.

\section{Introdução}

Atualmente a economia de Itaqui está fortemente relacionada à monocultura do arroz irrigado. Lima (2011) calcula que cerca de $80 \%$ da economia municipal de Itaqui advém da rizicultura e que o restante, 20\%, fica a cargo da pecuária, da suinocultura e de outras culturas permanentes e temporárias, tais como milho, soja, uva, linho, sorgo e laranja.

Conforme dados do Instituto Rio Grandense do Arroz (IRGA), na safra 2011/12, Itaqui produziu cerca de 760mil toneladas de arroz, abaixo apenas de Uruguaiana (950 mil toneladas). Nesse período, o Estado produziu 7.709.079 milhões de toneladas de arroz, com a Fronteira Oeste ocupando o primeiro lugar no ranking da produção do Estado (IRGA, 2012). No entanto, os índices da safra de 2012/13 apontam que o Municipio de Itaqui passará a ser o maior produtor de arroz do País, com área plantada de 81.984 hectares, ultrapassando Uruguaiana, com 80.356, até então líder deste setor.

É importante destacar que, além de produzir, os rizicultores em Itaqui mantêm a cadeia produtiva desse grão, das grandes áreas de cultivo de arroz até o seu beneficiamento industrial. Isso reflete constituição fundiária municipal, traduzida por Lima (2011, p. 11): “o Município, hoje, apresenta uma grande concentração de renda, cujas origens remontam as grandes propriedades rurais e que acabam se tornando os verdadeiros conglomerados industriais". Para Dufumier (2007, p. 26), "o desenvolvimento rural é, em primeiro lugar, um encadeamento de transformações técnicas, ecológicas, econômicas e sociais". Conforme as ideias desse autor, para 
entender a dinâmica atual da economia rural do município, baseada na rizicultura, é preciso entender a situação passada, no caso os sistemas agrários, e as suas contradições presentes para prever as tendências socioeconômicas futuras.

Assim, compreender essa realidade agrária torna-se de suma importância neste estudo, que remete à dinâmica local a partir dos sistemas agrários, possibilitando o entendimento dos fatores que tornaram a rizicultura um monocultivo na região.

\section{2 Área de estudo e procedimentos metodológicos}

O Município de Itaqui situa-se na região da Fronteira Oeste do Rio Grande do Sul, distante $670 \mathrm{~km}$ de Porto Alegre, capital do Estado. Possui uma área territorial de $3.404,047 \mathrm{Km}^{2}$, e 38.166 habitantes, sendo que a maioria $(87,3 \%)$ reside na área urbana. Conforme o Mapa do Macrozoneamento Ambiental do Rio Grande do Sul ${ }^{6}$, elaborado pela Secretaria de Planejamento, Gestão e Participação Cidadã (SEPLAG), em 2008, com o objetivo de expressar os principais padrões de uso e ocupação do solo, de cobertura vegetal e de relevo, o Município de Itaqui encontrase na macrozona do Planalto Meridional.

Figura 1 - Localização geográfica do Município de Itaqui no Estado do Rio Grande do Sul

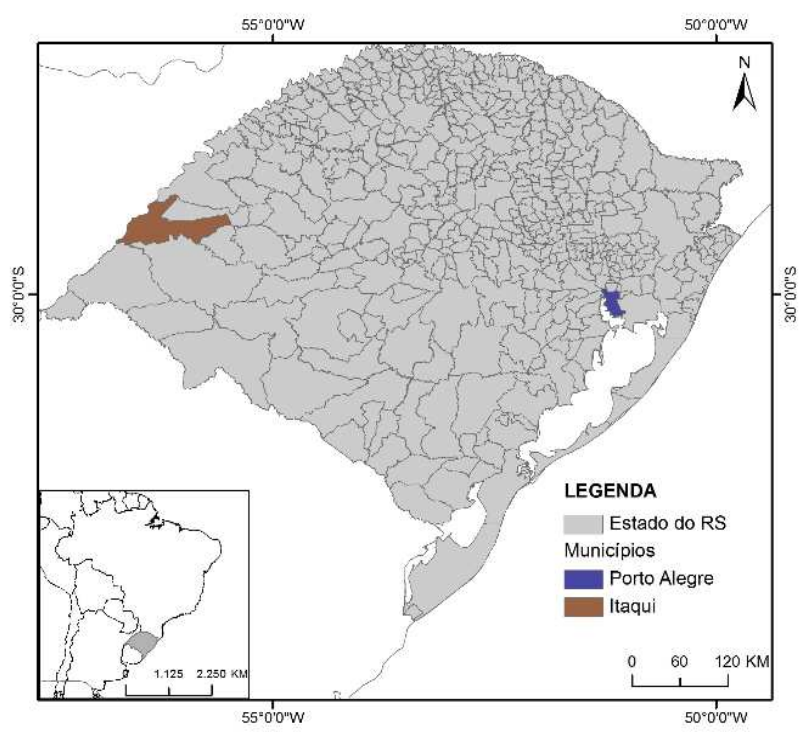

Fonte: Wikimedia Commons (2013).

\footnotetext{
${ }^{6}$ O Macrozoneamento utilizou como base de informações imagens de satélite dos anos de novembro e dezembro de 1999 e fevereiro de 2000; o mapa geomorfológico do Projeto RADAMBRASIL e o Mapa Altimétrico do Rio Grande do Sul.
} 
A região em que se encontra Itaqui caracteriza-se predominantemente pelo uso agrícola intensivo do solo no verão, basicamente ocupado por lavouras de arroz, e campos subarbustivos. Geomorfologicamente, caracteriza-se por apresentar uma superfície ondulada que antigamente era coberta por florestas e, em menor grau, por campos sujos. De acordo com o IRGA (2013), Itaqui possui o clima temperado do tipo subtropical (IRGA, 2013), classificado como mesotérmico úmido, caracterizado por verões secos e quentes, e invernos frios, com chuvas bem distribuídas. $O$ índice pluviométrico do Município é de aproximadamente $2.500 \mathrm{~mm}$ por ano. O território municipal pertence a duas bacias hidrográficas. São elas: bacia hidrográfica dos rios Butui-Icamaquã e bacia hidrográfica do rio Ibicuí. Ambas fazem parte da Região Hidrográfica do rio Uruguai e estão localizadas no Bioma Pampa. O cultivo do arroz é praticado em terras de várzeas e nas chamadas terras baixas, conhecidas como terrenos de baixa altitude, nos quais a curvatura topográfica desenvolve uma tipologia de coxilhas, própria para a adaptação da rizicultura. O cultivo do arroz irrigado é realizado em solos hidromórficos, os quais têm como principal característica a deficiente drenagem natural, normalmente restrita pelo relevo predominantemente plano, que apresenta uma camada de baixa permeabilidade.

Conforme o Censo Agropecuário do IBGE de 2010, 95\% da área territorial de Itaqui pertencem à agricultura não familiar. Essa área divide-se entre 320 proprietários. Em relação às propriedades de agricultura familiar, que correspondem a menos de $5 \%$ da área, divide-se entre 344 produtores rurais. Observa-se que cerca de $75 \%$ das propriedades de agricultura familiar utilizam somente mão-de-obra familiar, e cerca de 25\%, a não familiar. Para o Sindicato Rural de Itaqui (2013), a estrutura fundiária itaquiense é entendida como um ponto negativo, devido à concentração das propriedades estarem nas mãos dos médios e grandes produtores rurais, assim excluindo os pequenos produtores da competitividade no setor rizícola.

Para o embasamento teórico deste trabalho, foram utilizadas obras de autores que tratam diretamente do tema principal do estudo, os sistemas agrários. Para isso, referenciam-se no texto autores como Miguel (2009), Silva Neto e Basso (2005), Mertz (2004) e Mazoyer e Roudart (2001). Para o fundamento teórico sobre as fases do Capitalismo, utiliza-se a obra de Lopes (2006), que trata dos períodos PréCapitalista e Capitalista, desde o século XVI até a fase atual. 
Nos estudos que almejam distinguir a realidade rural, é importante abordar o objeto de estudo de forma ampla e holística, permitindo analisar as inter-relações de causa e efeito entre os diferentes elementos, permitindo olhar suas complexidades, sem deixar de perceber as especificidades nem tampouco a noção global, que estão imbricadas na realidade dos fenômenos rurais.

Realizou-se um levantamento de dados secundários, a partir de levantamento de documentos históricos, estatísticos e cartográficos; livros, revistas, dissertações, teses, trabalhos acadêmicos e artigos junto a instituições de pesquisa, como o Instituto Riograndense do Arroz (IRGA), Associação Rio-grandense de Empreendimentos de Assistência Técnica e Extensão Rural (EMATER/RS) e Instituto Brasileiro de Geografia e Estatística (IBGE). Assim, por meio deste levantamento de revisão bibliográfica, bem como entrevistas com informantes chaves da região, foi possível encontrar as informações necessárias para a reconstrução da historicidade.

\section{Abordagem teórica-conceital dos sistemas agrários}

Inicialmente, cabe apontar dois pontos importantes ao tratar de sistemas agrários defendidos por Silva Neto e Basso (2005). O primeiro refere-se a sua aplicabilidade tal como objeto de estudo, e o segundo, a sua área de abrangência. Para esses autores, a Teoria dos Sistemas Agrários pode ser aplicada desde estudos puramente acadêmicos até a definição de intervenções para a promoção do desenvolvimento rural. Sendo assim, para que se possa compreender o que é um sistema agrário, é necessário distinguir a agricultura tal como ela se apresenta na realidade, ou seja, um objeto de observação e de análise, daquilo de que é observado. Enquanto objeto, a agricultura necessita de um conjunto de conhecimentos metodicamente elaborados como resultados da observação, delimitação e análise. Então, um sistema agrário não é um objeto real, diretamente observável, mas um objeto cientificamente elaborado, cuja finalidade não é retratar a agricultura em toda a sua complexidade, tarefa praticamente impossível, mas tornar esta complexidade inteligível segundo os objetivos específicos definidos (SILVA NETO; BASSO, 2005).

Conforme Miguel (2009), o conceito inicial de sistemas agrários foi elaborado por geógrafos, porém, na década de 1960, a Ciência Agronômica o reelaborou. 
Logo, o sistema agrário, definido no espaço e no tempo, passou a ser entendido como a maneira como utilizamos o meio, onde as forças de produção se adaptam às condições do clima e aos seres vivos de certo espaço, resultando na satisfação das necessidades sociais do momento.

Segundo Mazoyer e Roudart (2001), um sistema agrário é um modo de exploração do meio historicamente constituído e durável, um conjunto de forças de produção adaptado às condições bioclimáticas de um espaço definido e que responde às condições e às necessidades sociais do momento.

Para além de sua conceituação, é importante ressaltar a forma na qual ocorre o processo de evolução dos sistemas agrários. Para Miguel (2009), a evolução não ocorre de forma linear e completa:

\footnotetext{
as diferentes etapas de um processo de evolução e diferenciação dos sistemas agrários dificilmente eliminam resíduos de formas e modos de agricultura anteriores; e igualmente, que a temporalidade dos eventos nem sempre pode ser definida com precisão, persistindo períodos de sombreamento e de transição entre o novo sistema agrário emergente e o antigo sistema agrário em regressão e em vias de desaparecimento (MIGUEL, 2009, p. 34).
}

Segundo Mertz (2004), a teoria dos sistemas agrários teria como objetivo a criação de um corpo de conhecimentos capaz de se constituir em uma base conceitual teórica e metodológica a quem quer que tenha por objetivo intervir no desenvolvimento social e, principalmente, o intuito de auxiliar a pesquisa sobre o desenvolvimento da agricultura através da História.

Considerando que os sistemas agrários resultam de interferências advindas dos recursos ambientais, socioeconômicos, de infraestrutura e político-econômicos existentes e atuantes em uma determinada realidade, as reflexões desenvolvidas procuraram reconhecer a presença de tais fatores, a partir do seu reconhecimento nos sistemas agrários analisados.

\section{Pecuária}

O Pré-Capitalismo e o Capitalismo Industrial refletiram no modo de produção da região de estudo até meados do século XX, tornando os Sistemas Agrários encontrados naquele período parte da própria história capitalista. 
Destaca-se que o primeiro Sistema Agrário Indígena, apresentado a seguir, enquadra-se no Sistema Pré-capitalista, porém não terá a pecuária como principal matéria-prima. Nessa fase, os povos indígenas eram basicamente coletores, caçadores, agricultores, e não tinham a prática da criação do gado naquele tempo, o que poderá ser observado nos dois Sistemas seguintes: Sistema das Estâncias Jesuíticas e Sistema Agrário Sesmeiro. O Capitalismo Industrial aparecerá na região através das indústrias de charques (Saladeiros), que aparecerão com o capital inglês no primeiro quartel do século XX. Esse período caracteriza-se como Sistema Agrário das Charqueadas.

\subsection{Sistema agrário indígena}

Delazeri (2002) considera que cerca de 10 mil anos atrás, o homem já habitava a região da Fronteira Oeste do Rio Grande do Sul. Segundo esse autor, um grupo de indígenas começou a habitar as terras dos pampas, sendo que os homens se dedicavam à caça, enquanto as mulheres faziam a coleta de frutas e moluscos na beira dos rios. Devido às doenças epidêmicas, à curta vida que eles tinham, e as guerras com povos inimigos, que tentavam ocupar o mesmo território, o número desses habitantes declinava, e não se desenvolvia.

A partir de relatos históricos, encontrados na obra de Colvero e Assis (2012), no Rio Grande do Sul e região, havia distintos grupos indígenas no século XV. Dentre eles, Jê, Pampeano, Charrua e Guarani, que habitava boa parte do território gaúcho, inclusive a Fronteira Oeste. O povo Guarani era seminômade. Esses índios partiram da região amazônica, devido a uma grande seca, "desceram" pelos grandes rios até chegarem ao rio Uruguai, nas proximidades do atual território itaquiense. Segundo a FUNAI (2013), cerca de 300 mil indígenas já ocupavam o território sul riograndense, na época da chegada dos portugueses ao Brasil. Boa parte desses habitantes integrava a nação Guarani, povo que pertence ao grupo Tupi-Guarani. Esse grupo era denominado coletor/caçador/agricultor, assim enfatizando os traços da agricultura nessa região desde os primórdios.

Ao chegar ao Rio Grande do Sul, o Povo Guarani deu preferência à conquista da mata, pois não tinha interesse em conquistar o campo aberto por não conhecer técnicas suficientes para cultivar grandes áreas. Eles usavam a coivara, a queima da 
mata, para abrir clareiras onde cultivavam pequenas roças ou hortas. Os homens cortavam e queimavam a mata, e as mulheres faziam o plantio e a colheita. Sua técnica de cultivo era rudimentar, utilizando o plantio direto, logo a colheita e, em seguida, o abandono da área, depois de aproximadamente três anos de uso, por causa do inço (DELAZERE, 2002).

A produção de alimentos e dos implementos necessários para o cultivo obedecia a uma divisão sexual do trabalho. Isto é, algumas atividades eram tarefas exclusivamente femininas, e outras eram tarefas masculinas. Essa divisão varia de sociedade para sociedade, mas pode-se dizer que, frequentemente, a caça e a pesca são praticadas pelos homens, que também confeccionam os instrumentos utilizados para caçar e pescar, enquanto a coleta, o cultivo da terra, a produção de cerâmica e o preparo dos alimentos para consumo são feitos pelas mulheres.

Um povoado Guarani era formado por até seis choupanas, casas coletivas quase sempre feitas do mesmo material, troncos e folhas, e igual em tamanho e na organização. A forma das ocas era oval, e o tamanho suficiente para abrigar várias famílias aparentadas, em média o casal e dois filhos, que formavam um Clã, núcleo fundamental do povo Guarani. As casas ficavam distribuídas ao redor de um espaço coletivo central, onde se realizavam os festejos. Os povoados ficavam próximos, cerca de quinze quilômetros de distância entre um e outro. Cada grupo necessitava de uma área relativamente grande para coletar frutos e caçar. As aldeias mantinham comunicação entre si através de uma teia de caminhos abertos na mata. A convivência na aldeia e o sistema de parentesco que uniam as famílias, que moravam distantes, formavam a base da sociedade das trocas e do aproveitamento dos recursos distribuídos na mata. Esse Sistema Agrário Indígena findou-se com o início da fase da colonização, quando Portugal e Espanha usaram o trabalho dos padres jesuítas da Companhia de Jesus para converter os índios guaranis à fé cristã. Com o decorrer dos anos, os índios foram sendo incorporados à nova fase e acabaram sendo alvo das disputas entre as duas coroas ibéricas, o que será descrito no próximo Sistema. 


\subsection{Sistema das estâncias jesuíticas}

Para iniciarmos o entendimento desse sistema agrário, que ocorrerá entre os séculos XVII e XIX, é de fundamental importância inserir Itaqui no contexto das pesquisas que abordam o assunto em âmbito regional. Os trabalhos de Colvero e Assis (2012) e Serres (2010) são duas importantes obras direcionadas ao município de Itaqui no período histórico em estudo.

Após o acordo do Tratado de Tordesilhas (1494), quando Portugal e Espanha dividiram o chamado Novo Mundo que Colombo havia descoberto em 1492, ficou então determinado que as terras situadas a oeste de Laguna (SC) eram consideradas espanholas, tornando o atual Rio Grande do Sul um território da Espanha. Na fase de colonização, Portugal e Espanha usaram o trabalho dos padres jesuítas da Companhia de Jesus com o objetivo de converter os índios guaranis à fé cristã, de modo a garantir a navegação pelos rios da Bacia do Rio da Prata, o que era impossibilitado pelos indígenas que habitavam a região (COLVERO; ASSIS, 2012). As reduções jesuíticas foram criadas pelos padres jesuítas e implantadas na América do Sul pela primeira vez em 1609. No Brasil, no noroeste do Rio Grande do Sul, os jesuítas chegaram em 1626, liderados pelo Padre Roque Gonzáles de Santa Cruz, e iniciaram o processo de evangelização dos índios guaranis, na margem oriental do rio Uruguai, atendendo aos objetivos da Companhia de Jesus (SILVA NETO; BASSO, 2005).

Os jesuítas, em duas ocasiões conhecidas como ciclos missioneiros, tentaram estabelecer-se à margem oriental do rio Uruguai, território espanhol, com o objetivo de catequizar o povo Guarani pelo sistema das reduções. A primeira ocorreu entre os anos de 1626 a 1634, e a segunda, de 1682 a 1706. No primeiro ciclo missioneiro, surgiram 18 reduções, onde jesuítas e índios conviviam. Dessa primeira fase não restaram vestígios arquitetônicos, devido ao frágil material usado nas construções, sendo basicamente palha, madeira e barro. Esses povoados não conseguiram estruturar-se, devido à invasão dos bandeirantes paulistas, que vinham para o Sul em busca de mão-de-obra escrava. No segundo ciclo missioneiro, houve a fundação da Colônia do Sacramento, em 1680, no estuário do rio da Prata, pelos portugueses. Essa fundação tinha um cunho estratégico, pois os portugueses queriam, tanto quanto os espanhóis, usufruir do contrabando e também da prata 
oriunda da região de Potosi, que até aquele momento ficava nas mãos dos espanhóis, que exploravam todo o comércio na região (SILVA NETO; BASSO, 2005).

Com a fundação da Colônia do Sacramento, os portugueses tinham como principal objetivo participar do comércio da prata. $\mathrm{Na}$ tentativa de evitar o ataque dos portugueses e a presença dos índios charruas nas terras e no rebanho que os espanhóis, os jesuítas e os índios guaranis consideravam propriedades suas, os jesuítas iniciaram o seu retorno para o território que hoje é o Rio Grande do Sul. Desse modo, fundaram sete reduções jesuítico-guaranis, conhecidas como os Sete Povos das Missões, os quais fazem parte dos trinta povos das Missões Guaraníticas.

A Guerra Guaranítica foi considerada um grande movimento sobre as terras indígenas para assegurar a posse das grandes extensões de terra que havia nas reduções. Isso porque havia nelas enorme quantidade de gado, que foi introduzido no território pelos jesuítas espanhóis em sua primeira tentativa de fundar missões entre 1626 a 1636 e que havia se reproduzido livremente. Essa imensa reserva de gado, resultado da reprodução quase selvagem, ficou reconhecida como "Vacaria del Mar". Para Pesavento (1980), esse rebanho será o fundamento econômico básico dos conflitos pela apropriação territorial do Rio Grande do Sul. Conforme Pesavento (1980), o fundamento econômico básico de apropriação de terra gaúcha: a preia do gado xucro. Na caça ao gado xucro, defrontavam-se diferentes grupos, todos visando ao conflito maior entre Espanha e Portugal, que lutavam para conseguir a maior posse de terra possível (PESAVENTO, 1980, p. 47).

As duas nações ibéricas assinaram um novo Tratado, o de Santo Ildefonso, que determinava que a Colônia do Sacramento, os Sete Povos das Missões e parte da Província de São Pedro do Rio Grande do Sul pertenceriam à Espanha. Em 1801, foi assinado o Tratado de Badajós, ao findar a Guerra das Laranjas, na Península Ibérica, de acordo com o qual a coroa Lusa, por ter perdido o confronto, deveria entregar algumas possessões na península e também a Colônia do Sacramento para a Espanha. Contudo, o final da beligerância demorou a ser comunicado nas colônias, e Portugal avançou no processo de ocupação das missões. Esse fator veio a beneficiar Portugal, pois o que prevalecia era o sistema 
de Uti possidetis ${ }^{7}$ no qual quem tivesse ocupado de fato determinada região, teria o direito de posse dela (COLVERO; ASSIS, 2012).

O local onde está hoje o município de Itaqui pertencia à Redução Jesuítica de La Cruz, na outra margem do rio Uruguai. A Redução de La Cruz foi fundada em 1657 e fixou-se definitivamente no seu local atual a partir de 1700. Itaqui era um campo de pastoreio e criação de gado do Povo Jesuíta antes da definição das fronteiras (COLVERO; ASSIS, 2012). Os jesuítas, ao verificarem a necessidade da criação da redução, preocuparam-se com alguns atributos necessários para que a redução pudesse se desenvolver com o mínimo de problemas possíveis. Observaram, por exemplo, a fertilidade das terras, os locais' em que pudessem desfrutar um panorama bonito, visando sempre a ambientes propícios para reflexões e desenvolvimento da catequese para os índios reduzidos (SERRES, 2010).

Com a fundação de La Cruz, houve a necessidade da criação de uma estância para abastecimento dessa redução. Iniciou-se uma discussão entre a Redução de Yapeyu e a de La Cruz para o estabelecimento do local no qual seria criada tal estância. A Redução de Yapeyu cedeu, então, uma parte de suas terras, localizadas no lado Oriental do rio Uruguai, para que fosse estabelecida a Estância de La Cruz, o que mais tarde daria origem ao atual Município de Itaqui (SERRES, 2010). As belas construções jesuíticas, as plantações de erva-mate e de algodão ficaram abandonadas, e o gado passou a ser disputado por aventureiros portugueses e espanhóis, que também saquearam o resto das construções. O povo foi se dispersando, e, aos poucos, começou a perder os modos e costumes de sua cultura (SANTOS, 2008).

Destaca-se que o cultivo de algodão e de erva-mate não era realizado em território itaquiense, porém eram escoados pelo antigo porto de pedra, localizado no Município, que, no século XVIII, era uma das principais rotas de exportação dos produtos oriundos dos povos missioneiros. O fim das Reduções foi marcado pelo abandono dos Sete Povos das Missões. O povo Guarani e os jesuítas foram expulsos, em 1767, do território espanhol. A região referida entrou em decadência e, em 1801, foram ocupadas definitivamente pela Coroa portuguesa. Com essa retomada de posse das terras pela Coroa Portuguesa, o gado que se proliferou

\footnotetext{
${ }^{7}$ Sistema no qual quem estivesse sobre a região efetivamente instalado teria direito de posse sobre ela, uma espécie de usocapião (COLVERO; ASSIS, 2012).
} 
passou a pertencer à Coroa, e seria a base econômica do próximo sistema agrário que se instalaria, o Sesmeiro.

\subsection{Sistema agrário sesmeiro}

De acordo com Colvero e Assis (2012), o início do povoamento luso concretizou-se com a retomada da região pelo domínio português após inúmeros tratados. Assim, o atual território de Itaqui formou-se pelo controle do Rincão da Cruz, que fazia parte das Missões, patrimônio da Redução de La Cruz da Província de Corrientes, pelos portugueses no século XIX.

Essa retomada das terras pelos lusos se efetivou pela concessão das sesmarias $^{8}$ aos súditos portugueses, entre eles muitos militares. A partir de 1802, a região inicia o processo de concessão das sesmarias, sendo a Sesmaria Rocha o local destinado à fundação do povoado que deu origem ao atual Município de Itaqui.

As sesmarias eram terrenos incultos e abandonados, entregues pela Coroa Portuguesa, desde o século XVII, às pessoas que se comprometiam a colonizá-los dentro de um prazo previamente estabelecido. Para essas pessoas estava préestabelecido o pagamento do dízimo para a propagação da fé (SANTOS, 2008). Desde o ano de 1802, prolongando-se uma década após, militares envolvidos em lutas na defesa do território brasileiro para a Coroa receberam grandes lotes de terras nessa região de fronteira.

A partir de pesquisas de Santos (2008), podemos relatar dados sobre a divisão territorial das primeiras sesmarias itaquienses, entre as quais constam as mais antigas sesmarias em que estavam divididos os campos do antigo Rincão da Cruz. O município era distribuído em quatro distritos, até 1997, quando o quarto distrito foi desmembrado de Itaqui, tornando-se, então, o Município de Maçambará.

O Quadro 1 representa a divisão das sesmarias por distritos, e foi elaborado por Santos (2008). Cabe ressaltar que a divisão por distritos aconteceu após o período histórico em estudo neste capítulo, com intuito de organizar o município por regiões específicas para facilitar as suas localizações. O autor entende que essa

\footnotetext{
${ }^{8}$ Vocábulo sesmaria derivou-se do termo sesma, e significava $1 / 6$ do valor estipulado para o terreno. Sesmo ou sesma também procedia do verbo sesmar (avaliar, estimar, calcular) ou, ainda, poderia significar um território que era repartido em seis lotes, nos quais, durante seis dias da semana, exceto no domingo, trabalharam seis sesmeiros (SANTOS, 2008).
} 
divisão por distritos seria a mais sensata maneira de organizar a distribuição das sesmarias para o entendimento do leitor que não conhece a região.

Podemos destacar que as sesmarias da Tigana, Bororé, Santo Cristo e São Donato são remanescentes do período jesuítico em Itaqui. Manoel Pereira de Escobar era proprietário da primitiva estância jesuítica de Santa Maria da Tigana, por volta de 1821. Nesse ano, o território de Itaqui contava com 42 estâncias. No ano seguinte, 1822, D. Pedro I suspendeu definitivamente as concessões de sesmarias, e, na precisa data de 18 de setembro de 1850, foi promulgada a Lei de Terras. A partir da referida data, as terras somente seriam adquiridas através de compra, não sendo mais distribuídas como no início (SANTOS, 2008).

O povoado de Itaqui começou a ser organizado a partir de 1821, com um acampamento militar sob o comando do Capitão Fabiano Pires de Almeida, às margens do rio Cambaí, um tributário do rio Uruguai, devido às constantes cheias. Foi esse acampamento deslocado para acima da margem, juntamente com famílias emigradas da Argentina, trazidas pelo irmão de Fabiano, que deram início ao povoamento da região (SANTOS, 2008). Esse povoamento tinha a missão estratégica de fazer a vigilância da fronteira num período conturbado pelas relações pouco amistosas das coroas luso e espanhola. Foi então organizado o povoado em quatro ruas de sentido Norte/Sul e quatro de sentido Leste/Oeste (SANTOS, 2008). Em 1837, o povoado passava à categoria de Freguesia de São Patrício de Itaqui, ligada a São Francisco de Borja. 


\section{Quadro 1: Distribuição das primeiras sesmarias Itaquiense}

\begin{tabular}{|c|c|}
\hline $1^{\circ}$ DISTRITO & 2 DISTRITO \\
\hline $\begin{array}{l}\text { - Sesmaria Rocha - sede do povoado; } \\
\text { - } \quad \text { Sesmaria Antonio José; } \\
\text { - } \quad \text { Sesmaria Assumpção; } \\
\text { - Sesmaria Santa Maria (no lbicuí); } \\
\text { - Sesmaria São João do lbicuí. }\end{array}$ & $\begin{array}{l}\text { - } \quad \text { Sesmaria São Miguel; } \\
\text { - } \quad \text { Sesmaria Mariano Pinto; } \\
\text { - } \quad \text { Sesmaria Sociedade; } \\
\text { - } \quad \text { Sesmaria São Solano; } \\
\text { - } \quad \text { Sesmaria Bittencourt; } \\
\text { - } \quad \text { Sesmaria So Padre; } \\
\text { - } \quad \text { Sesmaria Ramão de Abreu; } \\
\text { - } \quad \text { Sesmaria São João; } \\
\text { - } \quad \text { Sesmaria Bão José; } \\
\text { - } \quad \text { Sesmaria Espinilho; } \\
\text { - } \quad \text { Sesmaria São Donato; } \\
\text { - Sesmaria Tuparahi. } \\
\end{array}$ \\
\hline 3 DISTRITO & $4^{\circ}=$ DISTRITO \\
\hline $\begin{array}{l}\text { - Sesmaria Santa Maria da Tigana; } \\
\text { - } \quad \text { Sesmaria Santa Rosa do Capão Grande; } \\
\text { - } \quad \text { Sesmaria Monte Alegre; } \\
\text { - Sesmaria Jacuí; } \\
\text { - } \quad \text { Sesmaria Bororé; } \\
\text { - Sesmaria dos Espinilhos; } \\
\text { - Sesmaria Guapohy; } \\
\text { - Sesmaria Itaó; } \\
\text { - } \quad \text { Sesmaria Santa Rosa. }\end{array}$ & $\begin{array}{l}\text { - } \quad \text { Sesmaria SantoChristo; } \\
\text { - } \quad \text { Sesmaria do Butuhy; } \\
\text { - } \quad \text { Sesmaria Piche; } \\
\text { - } \quad \text { Sesmaria de São Canuto; } \\
\text { - } \quad \text { Sesmaria das Éguas Morochins; } \\
\text { - } \quad \text { Sesmaria da Figueira; } \\
\text { - } \quad \text { Sesmaria Curuçu (Curuçupucu). }\end{array}$ \\
\hline
\end{tabular}

Fonte: Santos (2008).

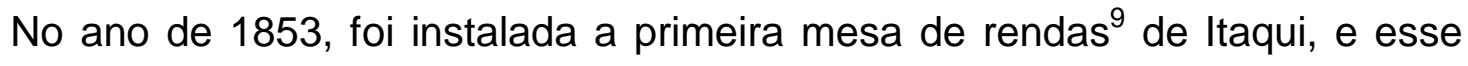
fator conseguiu demonstrar o potencial comercial do porto local, superando, por várias vezes, a arrecadação de exportações, tanto de São Borja quanto de Uruguaiana. Isso fez com que, no dia 6 de dezembro de 1858, essa Freguesia fosse elevada à categoria de Vila de Itaqui, desmembrando-se de São Borja.

Nesse tempo, a Vila possuía em torno de 400 casas, 6.031 habitantes, sendo 5.554 livres, 63 libertos e 1014 escravos. Em 03de maio de 1879, a Lei Provincial N.ำ 1.207 declara Itaqui como cidade. Segundo estudos de Colvero e Assis (2012), podemos observar que, no momento da emancipação da Vila de São Patrício de Itaqui, o número de libertos e escravos era de grande expressão, chegando a 17,8\%

\footnotetext{
${ }^{9}$ Termo usado por Colvero e Assis (2012) para relatar as reuniões ocorridas para esclarecimentos sobre as arrecadações de impostos.
} 
da população total. Considera-se que, em relação ao número de habitantes, esse número de escravos era expressivo para a época.

\subsection{Sistema agrário das charqueadas}

O charque, ou também a carne seca como é conhecido, era produzido no nordeste do Brasil desde o ano 1780. Seu grande propósito era alimentar escravos de várias regiões do Brasil. Com a ocorrência de uma grande seca no noroeste do País, que durou mais de três anos e dizimou grande parte da matéria-prima desse local, um fazendeiro chamado José Pinto Martins buscou novos locais para se instalar e continuar desenvolvendo essa atividade de charqueadas (SANTOS, 2008). O ciclo do charque, no Rio Grande do Sul, teve início com reflexos positivos na criação de gado. A produção do charque do saladeiro de Pelotas era transportada pelo rio São Gonçalo até o porto de Rio Grande, no qual a produção era exportada para Cuba. Somente um século e meio mais tarde, instalaram-se na fronteira oeste do Rio Grande do Sul três grandes saladeiros para a época, localizados nos Municípios de Uruguaiana, São Borja e Alto Uruguai (COLVERO; SERRES, 2009).

A existência de extensas áreas de campo aberto, localizadas na região de Itaqui, e a qualidade do gado brasileiro chamaram a atenção do inglês George Clark Dickinson e seus cinco filhos. A família possuía dois grandes saladeiros na cidade de Salto, República Oriental do Uruguai, onde eram abatidos gados vindos da Argentina e do Rio Grande do Sul. A região da Fronteira Oeste era propícia ao escoamento do charque. Os Dickinson escolheram muito bem o local no qual iriam instalar o saladeiro. Viram na região grandes oportunidades para a venda do charque, visto que o Município estava localizado no "corredor dos portos". Eles escolheram o local por ser de fácil acesso ao rio Uruguai, com conexões fronteiriças com a Argentina. Além disso, a linha férrea tinha ligações do saladeiro ao porto de Montevidéu. Esses fatores acarretaram o desenvolvimento do saladeiro de Itaqui (COLVERO; SERRES, 2009).

A partir do interesse nas terras gaúchas, os Dickinson finalmente instalaram em Itaqui o Saladeiro São Felipe ou Saladeiro Itaqui, como era conhecido. A compra da Estância Ibicuí, até então propriedade da senhora Maria Helena Fontoura Pinto, para a construção do saladeiro, que foi realizada entre os anos 1908 a 1910, com 
um custo aproximado de 80.000 libras esterlinas, foi intermediada por um tropeiro chamado Narciso Mello. A estrutura do Saladeiro possuía capacidade de abate de até 1.000 reses (cabeças) por dia para a produção do charque e seus derivados. $O$ saladeiro São Felipe abateu, no período de oito anos, 350.000 rezes, com uma produção média anual de 3.000 .000 de quilos de charque, 1.000 .000 de quilos de sebo, 50.000 quilos de graxa, 1.000 .000 de quilos de couro salgado e 40.000 quilos de língua em conserva (COLVERO; SERRES, 2009).

A estrutura do Saladeiro São Felipe era imponente para os padrões da época. Possuía grandes pavilhões de alvenaria, duas usinas elétricas e cinco barcos movidos a motor. O local tinha um ramal ferroviário de seis quilômetros de extensão, ligando-o à linha férrea da BGS (BrazilGreat Southern), no trecho Itaqui/Uruguaiana. Por possuir essas estruturas consideradas avançadas, o Saladeiro ficou conhecido como o maior empreendimento saladeril da Fronteira Oeste gaúcha e estava entre os maiores do Estado (COLVERO; SERRES, 2009). O principal estabelecimento das charqueadas, o Saladeiro São Felipe, foi a empresa que movimentou boa parte da economia do Município a partir dos anos de 1910 até meados de 1929. Foi fator importante para o desenvolvimento da exportação, do comércio e de grandes obras de Itaqui. Para a época, era a maior empresa instalada no território itaquiense. $\mathrm{O}$ gado advindo da pecuária era a principal matéria-prima desse Sistema. $\mathrm{O}$ charque e os seus subprodutos eram oriundos das oito fazendas da família, porém havia também a criação de equinos, para a lida no campo, e de ovinos, para o consumo da carne e da lã, além de animais domésticos de pequeno porte. Construído na mesma época da ascensão do Saladeiro, o Mercado Público tinha o objetivo de comercializar os produtos advindos daquele, sem deixar de lado a importância da exportação, importante marco para a história do Município, "o saladeiro São Felipe trouxe um período de intenso progresso para Itaqui, alavancando a construção do Mercado Público, fomentando o incremento da produção pecuária e atuando decisivamente na vida comercial e cultural do Município" (SANTOS, 2008, p. 50).

O transporte do charque, tanto via fluvial, quanto via ferroviária, foram de suma importância para o desenvolvimento da indústria saladeril, porém, a abertura da Barra do Rio Grande, que canalizou a produção estadual para seu único porto marítimo, elevando os custos da distribuição do produto e da aquisição de matériaprima, dificultou a comercialização e, consequentemente, a produção do charque. $O$ 
saladeiro São Felipe operou firmemente por 20 anos, finalizando suas atividades no ano de 1930. Esse fim foi devido à influência de muitos fatores, destacados por ordem de importância, segundo Colvero e Serres (2009): $1^{\circ}$ Abertura da Barra do Rio Grande, que canalizou a produção estadual para seu único porto marítimo; $2^{\circ}$ Consequência da lei da Nacionalização do Charque, em 1928, que impediu a saída do produto nacional pelos portos estrangeiros, tendo como destino os portos brasileiros; $3^{\circ}$ Dificuldade da estrada de ferro (BGS) de arcar sozinha com 0 transporte da produção do saladeiro; $4^{\circ}$ Crescente concorrência da indústria frigorífica; $5^{\circ}$ Grande Depressão dos anos de 1930. Esses fatores levaram o Saladeiro São Felipe, e, consequentemente, Itaqui, à falência, dando fim ao Sistema Agrário das Charqueadas, que trouxe grande desenvolvimento ao Município naquele período. Encerrando a exclusividade econômica que existia com a criação de gado e das charqueadas da Fronteira Oeste do Rio Grande do Sul, abre-se espaço para a inserção da agricultura, com o início do plantio de milho, linho e trigo, em meados de 1920, e logo após com a inserção do arroz, em 1930.

\section{Rizicultura: sistema agrário inicial e o sistema agrário contemporâneo}

A terceira fase capitalista, a monopolista-financeira, iniciada no século $X X$, estende-se até os dias atuais. Com ela, veio um importante crescimento da economia capitalista com o processo de centralização dos capitais.

Grande parte dos lucros e do capital em circulação no mundo passa pelo sistema financeiro. A globalização permitiu as grandes produções, visando à redução de custos e à geração de capital. As análises sobre o processo de desenvolvimento do capitalismo financeiro na agricultura firmaram-se no aprofundamento da compreensão das transformações nas denominadas relações entre a agropecuária e a indústria. Nessa visão, o limite estrutural estabelece-se nas divisas das propriedades rurais, sobre as quais transbordam as forças produtivas da agricultura derivadas da ampliação e da agregação de valor pelo processamento agroindustrial de matérias-primas rurais e pelo crescimento do uso de insumos e máquinas nos processos agropecuários (GONÇALVES, 2004). As atividades produtivas e a geração de capitais alargam-se para fora das porteiras das fazendas, no proliferar de fábricas de insumos e máquinas de processamento agroindustrial, 
que respondem por uma parcela expressiva do trabalho e da renda empregados na agricultura (GONÇALVES, 2004).

O Município começou a traçar sua história agrária orizícola pouco antes do ano de 1930, por Nabor Salgado, nas várzeas do rio Cambaí (SANTOS 2008). início do cultivo do arroz irrigado foi um marco para a economia itaquiense, uma espécie de divisão entre duas épocas: uma antes do cultivo do arroz, quando o sistema agrário era assentado principalmente na pecuária, e após o cultivo do arroz, quando esse cultivo começou a ganhar forças, a partir de 1950. Porém, o salto do crescimento da rizicultura ocorreu em 1970, quando chegaram ao Município as transformações tecnológicas oriundas da Revolução Verde. Poucos anos antes, no período em que precede os cultivos orizícolas, já se tinham registros da inserção de outras lavouras em Itaqui.

Usavam-se, no cultivo do milho, ferramentas manuais e tração animal, com arados de aiveca, porém esta prática não teve êxito, visto que os colonos abandonaram a lavoura antes da maturação do milho. No entanto, o produtor tentou novamente produzir a cultura, dessa vez com dezessete famílias brasileiras, italianas e russas, em 500 hectares de terra, atividade que durou até 1924 quando os colonos, com algum capital, se dispersaram. Em 1920, implantou-se no Município a citricultura na Fazenda Alto Uruguai, propriedade do Coronel Euclides Aranha. No mesmo ramo das frutas cítricas, estão inseridos os pomares de laranjeiras, de propriedade do senhor Atílio Mandadore, que cultivava em suas terras aproximadamente 26.000 pés de laranjeiras (SANTOS, 2008). No ano 1937, iniciouse o processo de beneficiamento e exportação da laranja, através de incentivos vindos da Prefeitura Municipal e do Estado. No entanto, as exportações não obtiveram êxito no seu objetivo devido aos impasses alfandegários. A falta de escoamento do produto e de incentivos fiscais resultou no desestímulo dos produtores, aprofundado pelo ataque fulminante de gafanhotos, que acabou destruindo totalmente os pomares e encerrando o cultivo de frutas cítricas em larga escala em Itaqui (SANTOS, 2008). Em 1929, iniciar-se-á no Município o processo de mecanização nas lavouras, inicialmente com os cultivos de linho, milho e trigo. $O$ agricultor Narciso produziu, em suas propriedades, os três cultivos em aproximadamente 2.000 hectares, nos Distritos itaquienses de Bororé Recreio e 
Tuparaí, com o total de onze famílias russas, que migraram para o Município para trabalhar na lavoura (SANTOS, 2008).

Segundo Delazeri (2002), devido à falta de terras em grande escala na região central do Rio Grande do Sul, na qual predominava a colonização alemã e italiana em pequenas propriedades, os imigrantes italianos e alemães viram, na fronteira oeste gaúcha, uma grande oportunidade de cultivarem em extensas áreas de campo aberto e várzea, o que facilitava a irrigação do arroz pelas condições do solo. A imigração teve ênfase no período de 1930 a 1960, agregando novos costumes à população local, que, na sua maioria, eram descendentes de castelhanos, espanhóis e portugueses. Esses imigrantes trouxeram os costumes das colônias para os pampas, dentre eles a diversidade de cultivos advindos das pequenas propriedades coloniais, como os pomares, as hortas, as criações de animais domésticos e a produção de produtos caseiros, como queijos, morcela, linguiça, compotas, conservas (SINDICATO RURAL DE ITAQUI, 2013).

A partir de dados do Sindicato Rural de Itaqui (2013), sabe-se que, por volta de 1953, já se usava a prática da inseminação artificial, com resultados excelentes e genética apurada. Nesse mesmo ano, um grupo de 11 produtores itaquienses criou a COPIL (Cooperativa Agropecuária Itaquiense Ltda.), por sentirem a necessidade de comercializar os subprodutos advindos da ovinocultura, prática que também teve ascensão nesse Sistema Agrário Inicial. Aos poucos, as plantações de arroz foram transformando a paisagem natural dos pampas e o trabalho em família, característica principal desse cenário, no qual a hereditariedade prevalecia, passando de geração a geração os conhecimentos de cultivos, criação, preparo do solo e inclusive os costumes sociais. A prática da diversidade de cultivos sempre esteve presente entre essas famílias imigrantes, mesmo com as grandes plantações, eles reservavam um espaço perto das moradias para o cultivo das hortas e pomares. Elas costumavam cultivar, nessas hortas e pomares, alimentos tais como mandioca, batata, abobrinha, milho, leguminosos e hortaliças em geral, e as demais variedades de frutas, como laranja, bergamota, abacaxi, pêssego, uva e acerola. Essas produções secundárias, tanto das hortas e pomares, quanto dos processados artesanalmente, como queijos e linguiças, sempre foram utilizadas para o consumo da família ou para a troca com vizinhos e empregados. 
O principal sistema de cultivo era o arroz, pois as condições climáticas e topográficas eram propícias ao cultivo. O sistema de irrigação, inicialmente, era realizado através de vias fluviais, com madeiras colocadas em valos que levavam a água até a lavoura. Essa água era retirada do rio e impulsionada às plantações através de bombas movidas a diesel. Como esse sistema que levava água até as lavouras não era muito proveitoso, desperdiçava-se muita água no caminho, porém a rica quantidade de rios na região facilitava o cultivo desse grão. Os produtores, tanto os que plantavam em grandes áreas, como os que plantavam em áreas menores enfrentavam alguns empecilhos na época das cheias, pelo fato de que o sistema de irrigação primário não possibilitava a remoção das bombas e nem dos encanamentos, visto que este sistema era fixo no solo, tornando-se vulnerável às cheias e às variações climáticas, muito comuns na região.

Nas lavouras, o solo era revolvido com arados puxados a boi, tratores que tinham implementos, como discos e grades. Na época da colheita, a mão-de-obra envolvia até 120 homens para uma média de, aproximadamente, 200 ha, que utilizavam instrumentados como foices e enxadas. $O$ arroz colhido era retirado da lavoura com auxílio de carroças puxadas a boi, depois era levado até o secador, ensacado e colocado nos caminhões para a comercialização.

Segundo relatos do entrevistado, a partir dos anos 60, a área de plantio começou a ser de maior escala, aproximadamente 600 hectares (ha) de terras por produtor, sendo arrendada ou de posse. Eram dedicados ao cultivo de cereais e oleaginosos aproximadamente 200 ha de terras, que serviriam para alimentação dos animais e da família. A convivência com vizinhos possibilitava a troca de experiências nas atividades realizadas, a permuta de mão-de-obra e de instrumentos agrícolas aprimorava os manejos e, cada vez mais, os sistemas de cultivos. Ainda utilizavam instrumentos agrícolas basicamente manuais, ferramentas como foices, enxadas, machados e arados puxados a bois, tendo como principal instrumento a mão-de-obra contratada. Porém, nesse período, já havia a introdução dos primeiros implementos "modernos" no Município, mas não eram todos os produtores que tinham a posse desses implementos no início.

O produtor entrevistado destaca que, nesse período, as transformações ocorreram na paisagem natural dos campos, visto que, com os avanços da tecnologia, cada vez mais aumentavam as áreas cultivadas. Assim, a mata ciliar 
existente foi removida quase totalmente, a mata costeira do rio foi derrubada e sua madeira aproveitada nos antigos secadores. De 25 metros de mata ciliar, foram deixados aproximadamente 5 metros, influenciando muito na fauna da região, e, consequentemente, na redução de animais silvestres e matas nativas. Esse Sistema Agrário Inicial deu origem ao próximo Sistema, que está vinculado às grandes transformações tecnológicas e à difusão da tecnologia no campo; vinculando-se à propagação das lavouras orizícolas itaquienses.

Com a modernização dos equipamentos agrícolas, devido às transformações dos pacotes tecnológicos, aproveitou-se, cada vez mais, o rendimento do solo para o plantio. Por ser uma região de umidade elevada e características bioclimáticas propícias, o cultivo do arroz tornou-se a principal fonte de renda do Município. Os cultivos de soja e trigo em culturas ficaram em segundo plano, utilizados também em pequena escala para a correção do solo, durante o sistema de rotação de cultivos, juntamente com a pecuária.

Para Graziano da Silva (1996), essa fase foi marcada por uma transição da agricultura formada pelos "complexos rurais" para uma dinâmica comandada pelos "complexos agroindustriais". Essa fase do processo de modernização da agricultura foi caracterizada por transformações no âmbito das relações comerciais, dos processos produtivos e das estruturas sociais do Município de Itaqui. Na década de 1960, já operavam na região tratores de 50 a 70 HP e máquinas colheitadeiras. Algumas das dificuldades encontravam-se na armazenagem dos produtos oriundos das lavouras de trigo, soja e arroz-irrigado, e na diminuição da mão-de-obra contratada, fazendo com que grandes e pequenos produtores fundassem, em 30 de julho de 1963, a Cooperativa Agrícola Mista Itaquiense (CAMIL) em um armazém de $2.700 \mathrm{~m}^{2}$.

A CAMIL Alimentos S/A proporcionou inúmeros benefícios ao povo itaquiense, como empregos e uma maior assistência ao produtor, que passava a ter a capacidade de armazenagem de seu produto, facilitando a comercialização desse produto e a compra e assistência técnica de insumos para a sua lavoura. Outro fato importante ocorreu em 28 de maio de 1965, quando o Sindicato Rural de Itaqui iniciou suas atividades com exatos 20 sócios. Na mesma década da fundação da CAMIL Alimentos e do Sindicato Rural, veio para o Município a aviação agrícola, no final da década de 1960. A vinda da aviação tinha o intuito de acompanhar o 
crescimento do setor orizícola, visto que aumentavam cada vez mais a área das lavouras, necessitando rapidez nas aplicações de produtos químicos sobre as áreas plantadas. Na década de 1970, com o salto das inovações tecnológicas aplicadas na agricultura, as facilidades de acesso ao crédito rural e a propagação da energia elétrica no Município induziram os produtores a investirem pesado na difusão da tecnologia no campo. Investiram na aquisição de implementos modernos, com alta capacidade de produção, para agilizarem esse processo.

Segundo o IRGA (2011), no final do ano de 1977 e início de 1978, o Município contava com um rebanho de 316.900 bovinos, com raças europeias e asiáticas. $\mathrm{Na}$ ovinocultura, contava com 330.451 cabeças, com raças específicas para lã; na suinocultura, com 5.910 cabeças. Nesse período, o foco começava a girar em torno do abate desses animais. No início do ano de 1980, Itaqui teve o seu primeiro criatório de suinocultura particular e de grande porte, a agroindústria YARGO.

Itaqui sentiu os reflexos da crise dos anos de 1980, década em que a crise nacional abalou os sistemas de produção agrícola de todo o País. Após esse período, intensificava-se a aplicação de insumos e agrotóxicos nas lavouras da região com intuito de promover a produtividade, que estava em baixa. Com a aplicação de fungicidas, houve uma ampliação dessa produtividade, necessária em meio a dívidas de anos anteriores. Essa ampliação da produtividade nas lavouras orizícolas desencadeou a intensificação dos sistemas de irrigação e o aumento das áreas plantadas, e, por consequência, a degradação das margens dos rios e das áreas protegidas.

Na década de 1980, também se pôde observar que algumas propriedades particulares estavam se estruturando com secadores e silos para a armazenagem dos grãos. Nesse período, a proporção de arrendatários de terras era maior do que a de proprietários. O Sindicato Rural de Itaqui estima que, no período que precede a década de 1980, havia cerca de 400 produtores de arroz associados ao Sindicato, esse número de associados refere-se ao auge da modernização da agricultura itaquiense. Nos dias atuais, esse número não alcança 100 produtores associados, sendo eles arrendatários ou proprietários, predominando as propriedades classificadas, de acordo com os parâmetros do Sindicato Rural de Itaqui (2013), como médias e de grande porte, todas tendo como principal cultivo o arroz irrigado.

No ano de 1980, um grande produtor era aquele que possuía uma área de 
terra a partir de 200 ha. Já no ano de 1990, com essa mesma área, era considerado um médio produtor, e, a partir do ano de 2000, se possuísse área plantada abaixo dos 300 ha, era considerado pequeno produtor, para os parâmetros da região. Nos anos de 1990 e 2000, época em que a modernização já estava instalada na região, somente os produtores bem inseridos no setor orizícola e com estabilidade financeira permaneciam consolidados no ramo. Os maquinários disponíveis para esses anos são os tratores de até 200HP, os implementos agrícolas de grande porte, o nivelamento de taipas a "laser" e, consequentemente, a diminuição do número de funcionários.

A produção de arroz em Itaqui, desde a safra 1997/98, vem apresentando índices crescentes em termos de área plantada e rendimento, devido aos avanços tecnológicos, tanto em implementos quanto em novas técnicas de plantio e novas formas de administrar o empreendimento rural itaquiense. A elevação da produtividade tem feito com que os produtores, cada vez mais, busquem investir em suas propriedades para que continuem obtendo rendimentos na lavoura orizícola.

Destaca-se que a diminuição da área plantada e da produtividade, ocorrida no ano de 2007, deu-se devido a dois fenômenos climáticos ocorridos no Município, o El Niño e a ocorrência de grandes cheias nos rios, que prejudicaram o momento do plantio e, consequentemente, obrigaram os produtores a diminuírem a área plantada. $O$ fato isolado dessa safra não significa que houve grandes perdas irreversíveis, visto que a produção, apesar de não alcançar o objetivo, ainda estava dentro da média esperada pelos produtores (SINDICATO RURAL DE ITAQUI, 2013).

No decorrer dos anos, as safras vêm apresentando produtividade dentro dos parâmetros esperados, com altas e baixas flutuações de preços e decorrências muitas vezes desfavoráveis aos produtores, que acabaram vendendo o grão em baixo preço. Porém, no ano safra de 2005/06 houve uma elevada produção do grão, que, consequentemente, favoreceu os produtores rurais.

Atualmente a rizicultura é a principal fonte de renda do município (80\%), seguida pela pecuária, suinocultura, ovinocultura e outras culturas temporárias e permanentes, como a laranja e a uva (LIMA, 2011). Encontra-se também o cultivo de linho, trigo, sorgo, milho, soja, dentre outros, cultivados em parcelas menores e utilizados na correção do solo. De acordo com o IBGE (2009), as lavouras permanentes itaquienses compreendem o cultivo de laranja e uva, numa área que 
não atinge 30 ha. As lavouras temporárias apresentam uma boa diversidade no Município, sendo que o arroz ocupa o lugar de destaque, seguido pela soja, milho, trigo, linho, batata doce e a mandioca.

Nos últimos anos, Itaqui apresenta um significativo aumento na produção de arroz irrigado. O Município registrou aumentos na área plantada e na produtividade da lavoura orizícola, passando a ser considerado o maior produtor de arroz do Estado do Rio Grande do Sul até o ano safra de 2012/13, segundo dados do IRGA (2013). No entanto, esse aumento na área da lavoura orizícola não representou um aumento em relação à mão-de-obra empregada na atividade. Diante dos reflexos da modernização, utilizava-se um empregado para cada 20 ha de arroz plantados. $\mathrm{Na}$ atualidade, tem-se a relação de um empregado para cada 60 ha de arroz cultivados, tornando o trabalho desses profissionais cada vez menos procurado. Esse fator pode gerar um problema social, visto que esses trabalhadores tendem a migrar para outros ramos existentes na área urbana e, muitas vezes, não conseguem mais empregos no campo (SINDICATO RURAL DE ITAQUI, 2013).

Destaca-se para a Fronteira Oeste 0 maior parque industrial de beneficiamento e armazenamento de arroz da América Latina (IRGA, 2013). Na região, existem várias empresas especializadas em grãos, e Itaqui conta com grandes indústrias de beneficiamento do grão, entre elas a CAMIL S/A e a Josapar Alimentos. Também possui outras empresas de médio porte que estão em ascensão no Município, tornando-o o maior produtor nacional de arroz irrigado, ultrapassando Uruguaiana que, até o ano safra de 2012/13, liderava esse ranking (IRGA,2013). Em Itaqui, segundo dados obtidos no IRGA (2013), até 05/04/2013 foram semeados cerca de 97.117 hectares do grão, tendo como resultados, até o dado momento, cerca de 60.213 hectares de área colhida, representando $62,00 \%$ do total desta área. Estes números representam uma produtividade de média de 7.495 quilos por hectare.

Estima-se que houve uma redução equivalente de $20 \%$ a $25 \%$ na produtividade em relação à safra dos dois anos anteriores. Atualmente, em Itaqui, os produtores de arroz trabalham em uma conjuntura que abrange alguns cuidados com o meio ambiente, os quais não eram aflorados nas décadas passadas. Muitos orizicultores têm a consciência de que é preciso preservar, ou ao menos degradar o 
mínimo possível o meio ambiente, visto que sofrem com os impactos que foram causados ao meio.

Utilizam, nesta conjuntura, a prática do cultivo mínimo, no qual o preparo do solo conta com um número mínimo de operações, normalmente duas gradagens superficiais e uma plaina. Esse sistema é praticado em mais de $90 \%$ das lavouras orizícolas do Município, pois o produtor tem consciência da necessidade de manter o mais intacta possível a estrutura do solo para mantê-la nutritiva (SINDICATO RURAL DE ITAQUI, 2013).

No entanto, o Município precisa intensificar a conscientização do uso de outorgas de água e licenciamento ambiental, bem como respeitar os limites estabelecidos pelo Código Florestal em relação às Áreas de Preservação Permanente (APP's) e reserva legal. Estas práticas vêm sendo mais fiscalizadas e cobradas no Município, exigindo os orizicultores a se adequarem às normas e leis estabelecidas. É importante destacar programas e projetos que vêm sendo implantados no Município para melhor reaproveitamento e conservação dos recursos naturais. O "Projeto 10" do IRGA, hoje com a produtividade média de 7.800 kg/ha, cuja finalidade é alcançar a produção de 10 mil quilos de arroz por hectare, conta com uma lavoura tecnificada e maquinários modernos, também exige práticas ambientais vigentes e a aplicação de agrotóxicos sob orientação agronômica (IRGA 2013).

Para isso, são aplicadas diversas técnicas recomendadas pelo Departamento de Assistência Técnica do IRGA, como época de plantio, adubação necessária e semente adequada, para uma lavoura com maquinários modernos e práticas ambientais menos agressivas ao meio ambiente, visando a uma lavoura mais sustentável (IRGA, 2013).

No entanto, mesmo se configurando com esta alta produtividade, nos últimos anos, questões relacionadas ao déficit hídrico vêm sendo apontadas como uma das causas que poderão levar ao não aumento da produtividade orizícola. O Rio Grande do Sul, no início da safra 2012/2013, foi marcado pela instabilidade motivada pelos baixos níveis dos mananciais hídricos, resultado da prolongada estiagem que sofreram os Municípios.

A flutuação dos preços está entre as maiores preocupações dos produtores em relação ao setor orizícola, Porém, nesta safra, os preços estão $20 \%$ superiores 
ao mesmo período do ano passado, sendo que, neste ano, a saca do arroz tipo 1 está $R \$ 32,69$, e, no ano anterior, $R \$ 27,25$ (IRGA, 2013). Essa nova condição do Município de maior produtor de arroz do País reforça a solidez de maior polo industrial da América Latina, motivando a propagação do setor orizícola para a Fronteira Oeste do Rio Grande do Sul.

\section{Considerações finais}

Na compreensão das realidades agrárias complexas deste trabalho, buscouse analisar como a evolução dos diferentes sistemas agrários do Município de Itaqui influenciaram no surgimento e na consolidação da rizicultura na economia local. Dessa forma, sente-se a necessidade de um estudo específico da dinâmica local para entender os fatores que tornaram a rizicultura um monocultivo na região da fronteira oeste do Rio Grande do Sul.

$\mathrm{Na}$ atualidade, o sistema agrário baseado no monocultivo de arroz irrigado não é muito diferente dos demais, pois esse cultivo, que está inserido em Itaqui desde meados de 1930, continua desenvolvendo-se na região e suprindo as necessidades desta geração de produtores orizícolas que vivem aqui e dependem economicamente desse sistema. Esses produtores entendem, cada vez mais, a necessidade de manter as características ambientais da região no qual estão inseridos. E boa parte desses produtores buscam práticas mais sustentáveis e produtivas, para manter a cultura em ascensão, e para conseguirem, primordialmente, manterem-se inseridos no setor, que sofre com as oscilações de preços do mercado.

Destacam-se a cultura itaquiense e os aspectos tácitos enfatizados com a imigração, como fatores influenciadores no entendimento de que, em Itaqui, o setor orizícola torna-se uma das grandes alternativas de desenvolvimento no campo. Dessa forma, os resultados obtidos nesta pesquisa focada nos sistemas agrários poderão servir de ferramenta a ser utilizada em ações que promovam o desenvolvimento rural e que privilegiem o Município no seu contexto. Poderá contribuir, também, para futuros trabalhos acadêmicos e para a geração de novos projetos que visem ao desenvolvimento socioeconômico e produtivo, municipal e regional. 


\section{Referências}

COLVERO, R. B.; ASSIS, A. A. O. Itaqui nas Fronteiras Ibero-Americanas: 18011889. São Borja: Faith, 2012.

COLVERO, R. B.; SERRES, H.S. O Saladeiro São Felipe de Itaqui: 1910-1930. Porto Alegre: Faith, 2009.

DELAZERI, J. Quando o Homem Chegou ao Sul do Brasil. Rancho Gaúcho. Disponível em: <http://www.ranchogaucho.com/historia1.cfm>. Acesso em: 9 mar. 2013

DUFUMIER, M. Projetos de desenvolvimento agrícola: manual para especialistas. Salvador: Edufba, 2007.

GONÇALVES, J. S. Agricultura sob a Égide do Capital Financeiro: Passo Rumo ao Aprofundamento do Desenvolvimento dos Agronegócios. Informações Econômicas, São Paulo, v. 35, n. 4, abr. 2005. Disponível em:

$<$ http://www.iea.sp.gov.br/out/publicacoes/pdf/tec1-0405.pdf>. Acesso em: 28 fev. 2013.

GRAZIANO DA SILVA, J. A nova dinâmica da agricultura brasileira. Campinas: Unicamp, 1996.

IBGE. Instituto brasileiro de geografia e estatísticas. Censo Agropecuário 2010, Itaqui, $R S_{\text {. }}$ Disponível em: <http://www.ibge.gov.br/cidadesat/topwindow.htm?1>. Acesso em: 17 mar. 2013.

IRGA. Instituto Riograndense de Arroz. Clima, Município de Itaqu $i$ - RS. Disponível em: <www.irga.rs.gov.br/>. Acesso em: 12 abr. 2013.

. Informações de Mercado, Safras. Disponível

em:<http://www.irga.rs.gov.br/\#>. Acesso em: 30 maio 2013.

LIMA, S. S. O Cultivo de Noz Pecã no Município de Itaqui - RS: o Estudo de Caso do Sítio Parintins. Trabalho de Conclusão de Curso (Graduação Tecnológica em Planejamento e Gestão para o Desenvolvimento Rural-Plageder) - Universidade Federal do Rio Grande do Sul, Porto Alegre, 2011.

LOPES, C. H. Surgimento e Consolidação Do Sistema Capitalista. Trabalho Acadêmico do Curso de Ciências Contábeis na FP, 2006. Disponível em: <http://www.ebah.com.br/content/ABAAAflfIAl/fases-capitalismo> Acesso em: 19 maio 2013.

MAZOYER, M.; ROUDART, L. História das agriculturas do mundo: do neolítico à crise contemporânea. Lisboa: Instituto Piaget, 2001.

MERTZ, M. A agricultura familiar no Rio Grande do Sul - um sistema agrário "colonial". Ensaios FEE, Porto Alegre, v. 25, n. 1, p. 277-298, abr. 2004. 
MIGUEL A. L. (Org). Dinâmica e Diferenciação dos Sistemas Agrários. UAB/UFRGSCurso de Graduação Tecnológica - Planejamento e Gestão para o Desenvolvimento Rural da SEAD/UFRGS. Série Ensino a Distância. Porto Alegre: UFRGS, 2009.

SILVA NETO, Benedito S.; BASSO, David (Orgs.). Sistemas Agrários do Rio Grande do Sul: análise e recomendações de políticas. ljuí: Unijuí, 2005.

SANTOS, P. C. dos. Agenda 150: Um passeio pelos carrilhões do tempo pretérito itaquiense. Itaqui: Novigraf, 2008.

SERRES,S. H. A Estância De La Cruz e sua Formação. 2010. Disponível em: $<$ http://www.eeh2010.anpuhrs.org.br/resources/anais/9/1279476107_ARQUIVO_AN PUH-AESTANCIADELACRUZESUAFORMACAO.pdf>. Acesso em: $\overline{3}$ maio $201 \overline{3}$.

SINDICATO RURAL DE ITAQUI. Disponível em: <http://www.sindicatoruraldeitaqui.com.br>. Acesso em: 15 mar. 2013.

WIKIMEDIA COMMONS. Disponível em:

<http://commons.wikimedia.org/wiki/File:RioGrandedoSul_MesoMicroMunicip.svg>. Acesso em: 15 mar. 2013. 